\title{
Circadian Post-transcriptional Control of Metabolism
}

\author{
Carla B. Green
}

\begin{abstract}
Circadian clocks control thousands of genes, which ultimately generate rhythms in signaling pathways, metabolism, tissue physiology and behavior. Although rhythmic transcription plays a critical role in generating these rhythmic gene expression patterns, recent evidence has shown that post-transcriptional mechanisms are also important. Here we describe studies showing that regulation of mRNA poly(A) tail length is under circadian control and that these changes contribute to rhythmic protein expression independently of transcription. Nocturnin, a circadian deadenylase that shortens poly(A) tails, contributes to this type of circadian post-transcriptional regulation. The importance of tail-shortening by Nocturnin is evident from the phenotype of mice lacking Nocturnin, which exhibit resistance to diet-induced obesity and other metabolic changes.
\end{abstract}

\section{Introduction}

Circadian clocks regulate and coordinate rhythms in behavior, physiology, biochemistry and gene expression in mammals (Pittendrigh 1981a, b; Akhtar et al. 2002; Panda et al. 2002; Storch et al. 2002; Ueda et al. 2002; Duffield 2003; Welsh et al. 2004; Reddy et al. 2006), allowing animals to synchronize appropriately to the environmental light:dark cycles. The mammalian circadian clock is composed of an intracellular feedback mechanism in which interlocking transcriptional-translational feedback loops generate the 24-h rhythms (reviewed in Lowrey and Takahashi 2004; Takahashi et al. 2008) and drive rhythms of 5-10\% of genes in a cell type-specific manner (Duffield 2003; Rey et al. 2011; Koike et al. 2012; Menet et al. 2012). This extensive control over mRNA expression results in rhythmicity of many cellular pathways, including many aspects of metabolism. Mutations that alter the clock have broad negative effects on the

C.B. Green $(\bowtie)$

Department of Neuroscience, University of Texas Southwestern Medical Center, Dallas, TX, USA

e-mail: Carla.Green@utsouthwestern.edu

P. Sassone-Corsi, Y. Christen (eds.), A Time for Metabolism and Hormones,

Research and Perspectives in Endocrine Interactions,

DOI 10.1007/978-3-319-27069-2_5 
organism, including insulin resistance and obesity (Rudic et al. 2004; Shimba et al. 2005; Turek et al. 2005; Green et al. 2008), some types of cancer (Fu et al. 2002; Gorbacheva et al. 2005; Hoffman et al. 2009, 2010a, b; Ozturk et al. 2009; Kang et al. 2010), cardiovascular disease (Curtis et al. 2007; Reilly et al. 2007) and sleep and affective disorders (Toh et al. 2001; Kripke et al. 2009; Srinivasan et al. 2009; Touma et al. 2009). Therefore, an understanding of the molecular mechanism of clocks in mammals is critical for the understanding and treatment of human health.

The components of the central circadian clock are transcriptional activators and repressors, and cyclic activation and repression drive the oscillation that comprises the pacemaker and generates the 24-h periodicity. In addition, these proteins drive rhythms in many other genes, through both direct and indirect transcriptional mechanisms. Although this transcriptional control is a major contributor to the resulting rhythms in mRNA levels, a number of recent studies have demonstrated that post-transcriptional regulation also must play an important role. For example, a large percent of rhythmic mRNAs in liver do not have rhythmic pre-RNAs (Koike et al. 2012; Menet et al. 2012) and, in mouse liver, almost $50 \%$ of the rhythmic proteins do not have rhythmic steady-state mRNA levels (Reddy et al. 2006). Moreover, circadian rhythms can exist in red blood cells devoid of nuclei (O'Neill and Reddy 2011; O'Neill et al. 2011). Therefore, regulatory mechanisms beyond transcription can also drive rhythmic physiology.

\section{Post-transcriptional Mechanisms}

Although transcription drives mRNA synthesis, the ultimate protein expression patterns also reflect regulation at many other levels (Fig. 1). Even as the mRNA is being transcribed, large complexes of proteins associate with the nascent transcript and regulate the efficiency and pattern of splicing, the choice of $3^{\prime}$-end cleavage site and polyadenylation (Pawlicki and Steitz 2010). The mature transcript undergoes further regulation during nuclear export, cytoplasmic localization, RNA stability and translation. The importance of post-transcriptional regulation has become clear over the last decade, with the discovery of many RNA binding proteins, specific types of ribonucleases, and the extensive machinery that conducts microRNA-mediated control of mRNA stability and translation. Although significant progress has been made in this area, understanding of post-transcriptional mechanisms still lags behind that of transcriptional processes.

The poly(A) tails at the $3^{\prime}$-end of most eukaryotic mRNAs are thought to be important for controlling translatability and stability, and one post-transcriptional regulatory mechanism is to modulate the length of these tails. Indeed, regulation of poly(A) tail length has been shown to play critical roles in many biological processes, including oocyte maturation, mitotic cell cycle progression, cellular senescence and synaptic plasticity (Gebauer et al. 1994; Groisman et al. 2002, 2006; Huang et al. 2002, 2006; Novoa et al. 2010). Changes in poly(A) tail length can occur at many points during the lifetime of an mRNA. Long poly(A) tails of 


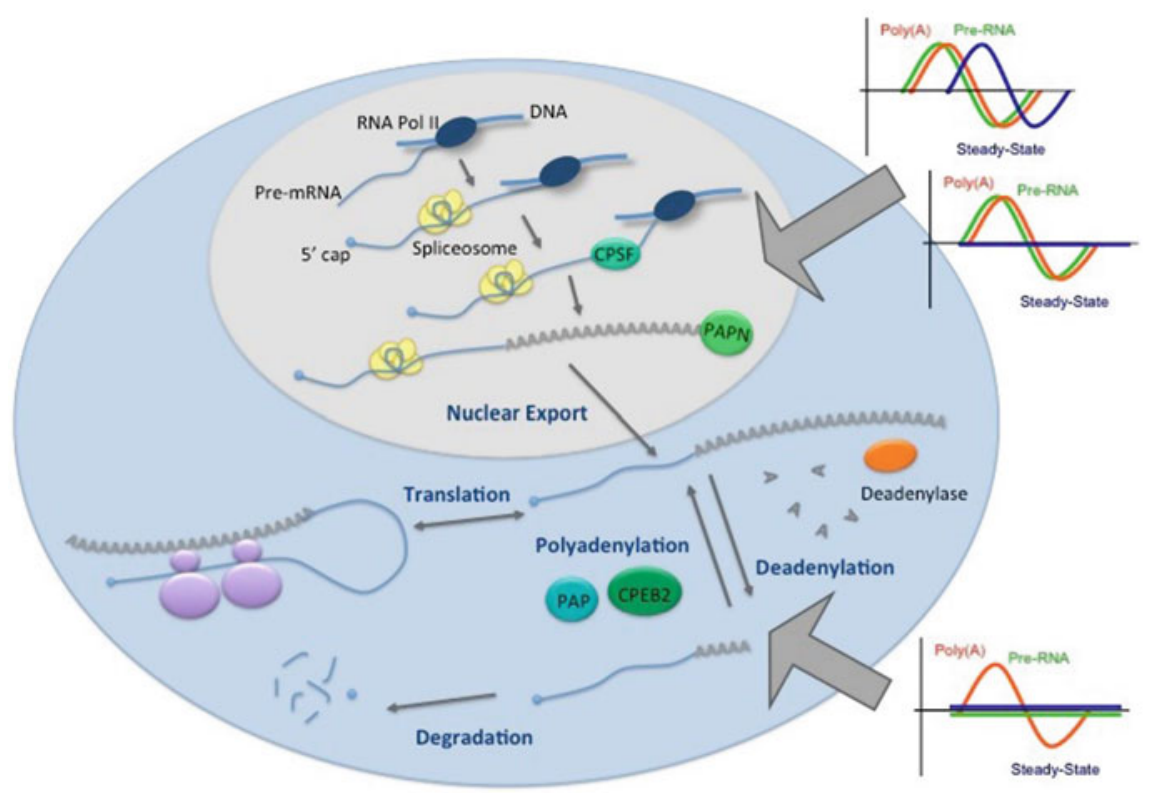

Fig. 1 Post-transcriptional regulation controls expression at many steps throughout the lifetime of the mRNA, and rhythms in poly(A) tail length can result from transcriptionally coupled mechanisms and cytoplasmic mechanisms (Kojima et al. 2012)

about $250 \mathrm{nt}$ are initially added to the nascent transcript in the nucleus following the $3^{\prime}$-end cleavage (Kuhn and Wahle 2004). Following export out of the nucleus, a protein called cytoplasmic poly(A)-binding protein (PABPC) binds to the tail and stabilizes the mRNA. Through direct interactions with the translation-initiation factor eIF4G, which in turn binds to the cap-binding protein eIF4E, PABPC is thought to facilitate translation initiation by forming a "closed-loop" circular structure (Kuhn and Wahle 2004). Removal or shortening of the tail by a specific class of ribonucleases called deadenylases can, in turn, result in translational silencing and, in some cases, mRNA degradation. Alternatively, cytoplasmic polyadenylation can, in some cases, lengthen the tail of an mRNA that was previously shortened and stabilize it and render it translationally competent (Richter 2007).

\section{Circadian Control of poly(A) Tail Length}

Daily variations in poly(A) tail length were reported for two mRNAs (Robinson et al. 1988; Gerstner et al. 2012), causing us to wonder whether the circadian clock uses this mechanism more broadly to regulate gene expression posttranscriptionally. Therefore, we fractionated mRNAs from mouse livers collected 
at various circadian times into pools of mRNAs with short ( $\sim 50 \mathrm{nt})$ and long (>100 nt) poly(A) tails (Kojima et al. 2012) using a modification of an oligo (dT) affinity chromatography method with differential elution stringencies (Meijer et al. 2007). These pools of mRNAs, along with a non-fractionated total poly(A)+ control, were subjected to microarray analysis, and relative tail-length was determined by the ratio of expression of each mRNA in the long vs. short tail pools (normalized for expression level using the total poly(A)+ expression level). Using this method, followed by independent validation, we identified several hundred mRNAs that exhibited robust changes in poly(A) tail length over the course of the circadian day.

Further characterization of these mRNAs revealed that they fell into three general classes (Fig. 1). The first class contained mRNAs that were transcribed rhythmically and also exhibited rhythms in their overall steady-state levels. The second class was also transcribed rhythmically but these mRNAs had long halflives and therefore were not rhythmic at the steady-state level. The third class of mRNAs with rhythmic poly(A) tails were not rhythmic at either the level of synthesis or at the steady-state level; these mRNAs appear to be long-lived and have poly(A) tails that are cyclically shortened and lengthened in the cytoplasm. Strikingly, in all the cases we tested, the poly(A) tail rhythms correlated with rhythmic protein levels, even in the cases where the steady-state levels of the mRNAs were not changing. These data suggest that circadian changes in poly (A) tail length can significantly contribute to rhythmic protein synthesis, independent of transcription.

\section{Nocturnin Is a Circadian Deadenylase}

The mechanism by which the clock controls poly(A) tail length is not well understood and appears to involve different mechanisms at different circadian phases (Kojima et al. 2012). However, one strong candidate is the deadenylase Nocturnin (gene name, Ccrn4l; Green and Besharse 1996; Baggs and Green 2003), which is robustly rhythmic in many mouse tissues, with peak expression in the middle of the night (Wang et al. 2001; Garbarino-Pico et al. 2007; Kojima et al. 2010). Nocturnin is a member of the superfamily of deadenylases that includes CCR4, Nocturnin, Angel, and 2'PDE (Goldstrohm and Wickens 2008; Godwin et al. 2013), but Nocturnin has a distinct amino-terminus from the other members. Nocturnin is also unique among all deadenylases in its characteristic high amplitude rhythms, with nighttime peaks (most of the other deadenylases are arrhythmic or have very low amplitude rhythms that peak in the day) (Kojima et al. 2012). In addition, Nocturnin is unique in that it is an immediate early gene that is acutely induced by many stimuli (Garbarino-Pico et al. 2007). Given the difference in temporal and spatial expression patterns of the deadenylases (Yamashita et al. 2005; Morita et al. 2007; Wagner et al. 2007; Kojima et al. 2012) and the different phenotypes caused by disrupting specific deadenylases (Molin and Puisieux 2005; Morris 
et al. 2005; Green et al. 2007; Morita et al. 2007; Washio-Oikawa et al. 2007), it is likely that each deadenylase targets a specific set of transcripts, although the identities of these transcripts and the mechanisms by which they are targeted by a particular deadenylase are not well characterized.

\section{Loss of Nocturnin Results in Broad Metabolic Changes}

The importance of Nocturnin's contribution to circadian changes in poly(A) tail length was tested by generating mice lacking Nocturnin (Noc-/-; Green et al. 2007). These mice appeared normal and healthy when raised in standard conditions and bred well. However, when raised on a Western-style high fat diet, the $N o c-/-$ mice did not gain weight at the same rate as the wild-type mice and remained lean whereas the wild-type mice became obese (Fig. 2). The Noc-/mice had smaller fat pads and were protected from hepatic steatosis. Despite this resistance to diet-induced obesity, the Noc-/- mice did not eat less, were not more active, and did not show significant changes in whole body respiration as measured in metabolic cages (Green et al. 2007; Douris and Green 2008). These mice did, however, have changes in mRNA expression levels of many key metabolic regulators in the liver, often showing loss of rhythmicity of normally rhythmic genes. Nocturnin is likely not part of the core circadian mechanism, because the Noc-/mice had normal circadian locomotor rhythms and normal expression of the core clock genes in the liver. However, it is directly regulated by the core circadian transcription factor heterodimer CLOCK/BMAL1 and is, therefore, a direct output of the intracellular core circadian loop. In addition, it is regulated by systemic circadian signals, likely originating directly or indirectly from the core circadian pacemaker in the suprachiasmatic nucleus in the hypothalamus, because Nocturnin is one of only a few dozen rhythmic genes that maintain rhythmicity following
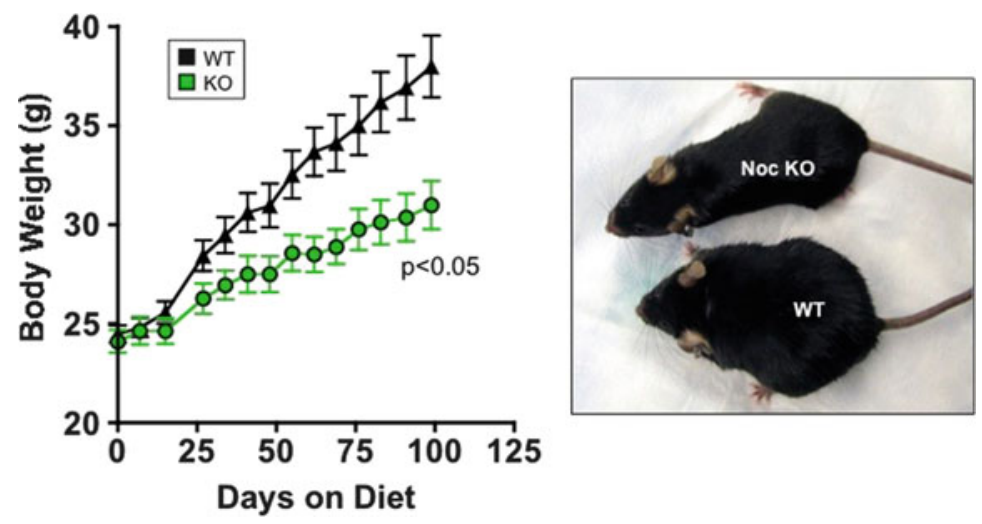

Fig. 2 Nocturnin knockout (KO) mice are resistant to diet-induced obesity. WT wild-type (Modified from Green et al. 2007) 
genetic disruption of the clock, specifically in the liver of mice (Kornmann et al. 2007).

Some clues to the mechanism behind the lean phenotype observed in the Noc-/ - mice came from examination of Nocturnin's role in the small intestine (Douris et al. 2011). Nocturnin is expressed throughout the digestive tract, but with particularly high levels in the upper part of the small intestine. As in other tissues, it is robustly rhythmic, peaking during the night - the time of maximal food intake in the nocturnal mouse. Pan and Hussain (2009) had previously shown that many of the transporters involved in macronutrient absorption by the intestinal enterocytes were under the control of the circadian clock. Accordingly, we found that lipid absorption in the wild-type mice was strongly circadian, with rapid appearance of newly ingested lipoprotein particles into the circulation when the mice were gavaged with olive oil at night, but slow and limited appearance when olive oil was administered during the day. In contrast, the Noc-/- mice had no rhythm in absorption and exhibited slow "daytime-like" absorption profiles following gavage given both night and day (Douris et al. 2011; Stubblefield et al. 2012). Furthermore, the enterocytes in the $N o c-/-$ mice accumulated large cytoplasmic lipid droplets, suggesting that dietary lipids were stored in these cells when Nocturnin was not present-at all times in the Noc-/- cells or during the daytime in wild-type mice. The mechanism by which this deadenylase regulates dietary lipid absorption is not clear, but several mRNAs that encode proteins involved in lipid droplet formation, breakdown and chylomicron assembly are dysregulated in the Noc-/- intestine, and some of these may be direct targets of Nocturnin deadenylase activity.

Nocturnin also plays important roles in other metabolically relevant tissues. In bone, Nocturnin interacts with a specific long isoform of Igfl mRNA, suppressing its expression (Kawai et al. 2010a). In bone-marrow stromal cells, Nocturnin is acutely induced more than 30 -fold by the peroxisome proliferator-activated receptor gamma (PPAR-gamma) agonist rosiglitazone, and Noc-/- mice have reduced marrow adiposity and high bone mass (Kawai et al. 2010b). In addition, overexpression of Nocturnin enhances adipogeneis in preadipocyte 3T3-L1 cells and negatively regulates osteogenesis in mouse osteoblastic MC3T3-E1 cells (Kawai et al. 2010b). Together these data suggest that Nocturnin plays an important role in the mesenchymal stem-cell lineage allocation that may ultimately influence adipogenesis and body composition.

\section{Conclusions}

The large contribution of post-transcriptional regulation to the generation and modulation of rhythmic mRNA and protein profiles has recently become apparent largely thanks to the use of genome-wide interrogation of rhythmic mRNA expression and transcriptional and post-transcriptional states. The ongoing development of innovative high-throughput methods for analyzing various nuances of gene expression (TAIL-seq, GRO-seq, CLIP-seq, and many more) will undoubtedly 
yield ever more information about how the clock controls the many layers of gene expression that drive the complex rhythmic physiology and behavior of mammals. We expect that new modes of post-transcriptional regulatory mechanisms will be uncovered and that these will be shown to play an important role in shaping these rhythms.

Nocturnin is likely only one of many post-transcriptional modulators that contribute to circadian expression profiles, but the profound metabolic phenotype in the Noc- $-/-$ mice shows that it is playing an important role in regulating circadian metabolic profiles. However, to understand how loss of Nocturnin causes these phenotypes, it will be critical to identify the relevant Nocturnin target mRNAs and to uncover how these target mRNAs are recognized by Nocturnin. Finally, the exact function of deadenylation by Nocturnin is still not clear. Although removal of tails has long been thought to target them for decay, it has recently been discovered that many mRNAs are maintained in the cell in short-tailed states that are quite stable. Are these short-tailed mRNAs translationally silent and waiting to have their tails lengthened in response to the appropriate signal or do they have some other function? Only time will tell...

Open Access This chapter is distributed under the terms of the Creative Commons AttributionNoncommercial 2.5 License (http://creativecommons.org/licenses/by-nc/2.5/) which permits any noncommercial use, distribution, and reproduction in any medium, provided the original author(s) and source are credited.

The images or other third party material in this chapter are included in the work's Creative Commons license, unless indicated otherwise in the credit line; if such material is not included in the work's Creative Commons license and the respective action is not permitted by statutory regulation, users will need to obtain permission from the license holder to duplicate, adapt or reproduce the material.

\section{References}

Akhtar RA, Reddy AB, Maywood ES, Clayton JD, King VM, Smith AG, Gant TW, Hastings MH, Kyriacou CP (2002) Circadian cycling of the mouse liver transcriptome, as revealed by cDNA microarray, is driven by the suprachiasmatic nucleus. Curr Biol 12:540-550

Baggs JE, Green CB (2003) Nocturnin, a deadenylase in Xenopus laevis retina: a mechanism for posttranscriptional control of circadian-related mRNA. Curr Biol 13:189-198

Curtis AM, Cheng Y, Kapoor S, Reilly D, Price TS, Fitzgerald GA (2007) Circadian variation of blood pressure and the vascular response to asynchronous stress. Proc Natl Acad Sci USA 104:3450-3455

Douris N, Green CB (2008) NOC out the fat: a short review of the circadian deadenylase nocturnin. Ann Med 40:622-626

Douris N, Kojima S, Pan X, Lerch-Gaggl AF, Duong SQ, Hussain MM, Green CB (2011) Nocturnin regulates circadian trafficking of dietary lipid in intestinal enterocytes. Curr Biol 21:1347-1355

Duffield GE (2003) DNA microarray analyses of circadian timing: the genomic basis of biological time. J Neuroendocrinol 15:991-1002

Fu L, Pelicano H, Liu J, Huang P, Lee C (2002) The circadian gene Period2 plays an important role in tumor suppression and DNA damage response in vivo. Cell 111:41-50 
Garbarino-Pico E, Niu S, Rollag MD, Strayer CA, Besharse JC, Green CB (2007) Immediate early response of the circadian polyA ribonuclease nocturnin to two extracellular stimuli. RNA 13:745-755

Gebauer F, Xu W, Cooper GM, Richter JD (1994) Translational control by cytoplasmic polyadenylation of c-mos mRNA is necessary for oocyte maturation in the mouse. EMBO J 13:5712-5720

Gerstner JR, Vanderheyden WM, LaVaute T, Westmark CJ, Rouhana L, Pack AI, Wickens M, Landry CF (2012) Time of day regulates subcellular trafficking, tripartite synaptic localization, and polyadenylation of the astrocytic Fabp7 mRNA. J Neurosci 32:1383-1394

Godwin AR, Kojima S, Green CB, Wilusz J (2013) Kiss your tail goodbye: the role of PARN, nocturnin, and angel deadenylases in mRNA biology. Biochim Biophys Acta 1829:571-579

Goldstrohm AC, Wickens M (2008) Multifunctional deadenylase complexes diversify mRNA control. Nat Rev Mol Cell Biol 9:337-344

Gorbacheva VY, Kondratov RV, Zhang R, Cherukuri S, Gudkov AV, Takahashi JS, Antoch MP (2005) Circadian sensitivity to the chemotherapeutic agent cyclophosphamide depends on the functional status of the CLOCK/BMAL1 transactivation complex. Proc Natl Acad Sci USA 102:3407-3412

Green CB, Besharse JB (1996) Identification of a novel vertebrate circadian clock-regulated gene encoding the protein nocturnin. Proc Natl Acad Sci USA 93:14884-14888

Green CB, Douris N, Kojima S, Strayer CA, Fogerty J, Lourim D, Keller SR, Besharse JC (2007) Loss of nocturnin, a circadian deadenylase, confers resistance to hepatic steatosis and dietinduced obesity. Proc Natl Acad Sci USA 104:9888-9893

Green CB, Takahashi JS, Bass J (2008) The meter of metabolism. Cell 134:728-742

Groisman I, Jung MY, Sarkissian M, Cao Q, Richter JD (2002) Translational control of the embryonic cell cycle. Cell 109:473-483

Groisman I, Ivshina M, Marin V, Kennedy NJ, Davis RJ, Richter JD (2006) Control of cellular senescence by CPEB. Genes Dev 20:2701-2712

Hoffman AE, Zheng T, Stevens RG, Ba Y, Zhang Y, Leaderer D, Yi C, Holford TR, Zhu Y (2009) Clock-cancer connection in non-Hodgkin's lymphoma: a genetic association study and pathway analysis of the circadian gene cryptochrome 2. Cancer Res 69:3605-3613

Hoffman AE, Zheng T, Ba Y, Stevens RG, Yi CH, Leaderer D, Zhu Y (2010a) Phenotypic effects of the circadian gene cryptochrome 2 on cancer-related pathways. BMC Cancer 10:110

Hoffman AE, Zheng T, Yi CH, Stevens RG, Ba Y, Zhang Y, Leaderer D, Holford T, Hansen J, Zhu Y (2010b) The core circadian gene cryptochrome 2 influences breast cancer risk, possibly by mediating hormone signaling. Cancer Prev Res (Phila) 3:539-548

Huang YS, Jung MY, Sarkissian M, Richter JD (2002) N-methyl-D-aspartate receptor signaling results in Aurora kinase-catalyzed CPEB phosphorylation and alpha CaMKII mRNA polyadenylation at synapses. EMBO J 21:2139-2148

Huang YS, Kan MC, Lin CL, Richter JD (2006) CPEB3 and CPEB4 in neurons: analysis of RNA-binding specificity and translational control of AMPA receptor GluR2 mRNA. EMBO J 25:4865-4876

Kang TH, Lindsey-Boltz LA, Reardon JT, Sancar A (2010) Circadian control of XPA and excision repair of cisplatin-DNA damage by cryptochrome and HERC2 ubiquitin ligase. Proc Natl Acad Sci USA 107:4890-4895

Kawai M, Delany AM, Green CB, Adamo ML, Rosen CJ (2010a) Nocturnin suppresses igf1 expression in bone by targeting the $3^{\prime}$ untranslated region of igf1 mRNA. Endocrinology $151: 4861-4870$

Kawai M, Green CB, Lecka-Czernik B, Douris N, Gilbert MR, Kojima S, Ackert-Bicknell C, Garg N, Horowitz MC, Adamo ML, Clemmons DR, Rosen CJ (2010b) A circadian-regulated gene, nocturnin, promotes adipogenesis by stimulating PPAR-gamma nuclear translocation. Proc Natl Acad Sci USA 107:10508-10513 
Koike N, Yoo SH, Huang HC, Kumar V, Lee C, Kim TK, Takahashi JS (2012) Transcriptional architecture and chromatin landscape of the core circadian clock in mammals. Science 338:349-354

Kojima S, Gatfield D, Esau CC, Green CB (2010) MicroRNA-122 modulates the rhythmic expression profile of the circadian deadenylase nocturnin in mouse liver. PLoS One 5:e11264

Kojima S, Sher-Chen EL, Green CB (2012) Circadian control of mRNA polyadenylation dynamics regulates rhythmic protein expression. Genes Dev 26:2724-2736

Kornmann B, Schaad O, Bujard H, Takahashi JS, Schibler U (2007) System-driven and oscillatordependent circadian transcription in mice with a conditionally active liver clock. PLoS Biol 5: e34

Kripke DF, Nievergelt CM, Joo E, Shekhtman T, Kelsoe JR (2009) Circadian polymorphisms associated with affective disorders. J Circadian Rhythms 7:2

Kuhn U, Wahle E (2004) Structure and function of poly(A) binding proteins. Biochim Biophys Acta 1678:67-84

Lowrey PL, Takahashi JS (2004) Mammalian circadian biology: elucidating genome-wide levels of temporal organization. Annu Rev Genomics Hum Genet 5:407-441

Meijer HA, Bushell M, Hill K, Gant TW, Willis AE, Jones P, de Moor CH (2007) A novel method for poly(A) fractionation reveals a large population of mRNAs with a short poly(A) tail in mammalian cells. Nucleic Acids Res 35:e132

Menet JS, Rodriguez J, Abruzzi KC, Rosbash M (2012) Nascent-seq reveals novel features of mouse circadian transcriptional regulation. eLife 1:e00011

Molin L, Puisieux A (2005) C. elegans homologue of the Caf1 gene, which encodes a subunit of the CCR4-NOT complex, is essential for embryonic and larval development and for meiotic progression. Gene 358:73-81

Morita M, Suzuki T, Nakamura T, Yokoyama K, Miyasaka T, Yamamoto T (2007) Depletion of mammalian CCR4b deadenylase triggers elevation of the p27Kip1 mRNA level and impairs cell growth. Mol Cell Biol 27:4980-4990

Morris JZ, Hong A, Lilly MA, Lehmann R (2005) twin, a CCR4 homolog, regulates cyclin poly (A) tail length to permit Drosophila oogenesis. Development 132:1165-1174

Novoa I, Gallego J, Ferreira PG, Mendez R (2010) Mitotic cell-cycle progression is regulated by CPEB1 and CPEB4-dependent translational control. Nat Cell Biol 12:447-456

O’Neill JS, Reddy AB (2011) Circadian clocks in human red blood cells. Nature 469:498-503

O’Neill JS, van Ooijen G, Dixon LE, Troein C, Corellou F, Bouget FY, Reddy AB, Millar AJ (2011) Circadian rhythms persist without transcription in a eukaryote. Nature 469:554-558

Ozturk N, Lee JH, Gaddameedhi S, Sancar A (2009) Loss of cryptochrome reduces cancer risk in p53 mutant mice. Proc Natl Acad Sci USA 106:2841-2846

Pan X, Hussain MM (2009) Clock is important for food and circadian regulation of macronutrient absorption in mice. J Lipid Res 50:1800-1813

Panda S, Antoch MP, Miller BH, Su AI, Schook AB, Straume M, Schultz PG, Kay SA, Takahashi JS, Hogenesch JB (2002) Coordinated transcription of key pathways in the mouse by the circadian clock. Cell 109:307-320

Pawlicki JM, Steitz JA (2010) Nuclear networking fashions pre-messenger RNA and primary microRNA transcripts for function. Trends Cell Biol 20:52-61

Pittendrigh CS (1981a) Circadian systems: general perspective. In: Aschoff J (ed) Biological rhythms, vol 4, 1st edn, Handbook of behavioral neurobiology. Plenum, New York, pp 57-80

Pittendrigh CS (1981b) Circadian systems: entrainment. In: Ascholl J (ed) Biological rhythms, vol 4, 1st edn, Handbook of behavioral neurobiology. Plenum, New York, pp 95-124

Reddy AB, Karp NA, Maywood ES, Sage EA, Deery M, O’Neill JS, Wong GK, Chesham J, Odell M, Lilley KS, Kyriacou CP, Hastings MH (2006) Circadian orchestration of the hepatic proteome. Curr Biol 16:1107-1115

Reilly DF, Westgate EJ, FitzGerald GA (2007) Peripheral circadian clocks in the vasculature. Arterioscler Thromb Vasc Biol 27:1694-1705 
Rey G, Cesbron F, Rougemont J, Reinke H, Brunner M, Naef F (2011) Genome-wide and phasespecific DNA-binding rhythms of BMAL1 control circadian output functions in mouse liver. PLoS Biol 9:e1000595

Richter JD (2007) CPEB: a life in translation. Trends Biochem Sci 32:279-285

Robinson BG, Frim DM, Schwartz WJ, Majzoub JA (1988) Vasopressin mRNA in the suprachiasmatic nuclei: daily regulation of polyadenylate tail length. Science 241:342-344

Rudic RD, McNamara P, Curtis AM, Boston RC, Panda S, Hogenesch JB, Fitzgerald GA (2004) BMAL1 and CLOCK, two essential components of the circadian clock, are involved in glucose homeostasis. PLoS Biol 2:e377

Shimba S, Ishii N, Ohta Y, Ohno T, Watabe Y, Hayashi M, Wada T, Aoyagi T, Tezuka M (2005) Brain and muscle Arnt-like protein-1 (BMAL1), a component of the molecular clock, regulates adipogenesis. Proc Natl Acad Sci USA 102:12071-12076

Srinivasan V, Pandi-Perumal SR, Trakht I, Spence DW, Hardeland R, Poeggeler B, Cardinali DP (2009) Pathophysiology of depression: role of sleep and the melatonergic system. Psychiatr Res 165:201-214

Storch K, Lipan O, Leykin I, Viswanathan N, Davis F, Wong W, Weitz C (2002) Extensive and divergent circadian gene expression in liver and heart. Nature 417:78-83

Stubblefield JJ, Terrien J, Green CB (2012) Nocturnin: at the crossroads of clocks and metabolism. Trends Endocrinol Metab 23:326-333

Takahashi JS, Hong HK, Ko CH, McDearmon EL (2008) The genetics of mammalian circadian order and disorder: implications for physiology and disease. Nat Rev Genet 9:764-775

Toh KL, Jones CR, He Y, Eide EJ, Hinz WA, Virshup DM, Ptacek LJ, Fu YH (2001) An hPer2 phosphorylation site mutation in familial advanced sleep phase syndrome. Science 291:1040-1043

Touma C, Fenzl T, Ruschel J, Palme R, Holsboer F, Kimura M, Landgraf R (2009) Rhythmicity in mice selected for extremes in stress reactivity: behavioural, endocrine and sleep changes resembling endophenotypes of major depression. PLoS One 4:e4325

Turek FW, Joshu C, Kohsaka A, Lin E, Ivanova G, McDearmon E, Laposky A, Losee-Olson S, Easton A, Jensen DR, Eckel RH, Takahashi JS, Bass J (2005) Obesity and metabolic syndrome in circadian clock mutant mice. Science 308:1043-1045

Ueda HR, Chen W, Adachi A, Wakamatsu H, Hayashi S, Takasugi T, Nagano M, Nakahama K, Suzuki Y, Sugano S, Iino M, Shigeyoshi Y, Hashimoto S (2002) A transcription factor response element for gene expression during circadian night. Nature 418:534-539

Wagner E, Clement SL, Lykke-Andersen J (2007) An unconventional human Ccr4-Caf1 deadenylase complex in nuclear cajal bodies. Mol Cell Biol 27:1686-1695

Wang Y, Osterbur DL, Megaw PL, Tosini G, Fukuhara C, Green CB, Besharse JC (2001) Rhythmic expression of nocturnin mRNA in multiple tissues of the mouse. BMC Dev Biol 1:9

Washio-Oikawa K, Nakamura T, Usui M, Yoneda M, Ezura Y, Ishikawa I, Nakashima K, Noda T, Yamamoto T, Noda M (2007) Cnot7-null mice exhibit high bone mass phenotype and modulation of BMP actions. J Bone Mine Res 22:1217-1223

Welsh DK, Yoo SH, Liu AC, Takahashi JS, Kay SA (2004) Bioluminescence imaging of individual fibroblasts reveals persistent, independently phased circadian rhythms of clock gene expression. Curr Biol 14:2289-2295

Yamashita A, Chang TC, Yamashita Y, Zhu W, Zhong Z, Chen CY, Shyu AB (2005) Concerted action of poly(A) nucleases and decapping enzyme in mammalian mRNA turnover. Nat Struct Mol Biol 12:1054-1063 